\title{
Spatially controlled cell adhesion on three-dimensional substrates
}

\author{
Christine Richter • Martina Reinhardt • Stefan Giselbrecht • Daniel Leisen • \\ Vanessa Trouillet • Roman Truckenmüller • Axel Blau • Christiane Ziegler • \\ Alexander Welle
}

Published online: 18 May 2010

(C) The Author(s) 2010. This article is published with open access at Springerlink.com

\begin{abstract}
The microenvironment of cells in vivo is defined by spatiotemporal patterns of chemical and biophysical cues. Therefore, one important goal of tissue engineering is the generation of scaffolds with defined biofunctionalization in order to control processes like cell adhesion and differentiation. Mimicking extrinsic factors like integrin ligands presented by the extracellular matrix is one of the key elements to study cellular adhesion on biocompatible scaffolds. By using special thermoformable polymer films
\end{abstract}

Christine Richter and Martina Reinhardt contributed equally to this work.

C. Richter $\cdot$ M. Reinhardt $\cdot$ S. Giselbrecht $\cdot$ D. Leisen •

A. Welle $(\square)$

Institute for Biological Interfaces,

Karlsruhe Institute of Technology (KIT),

P.O. Box 3640, 76021 Karlsruhe, Germany

e-mail: alexander.welle@kit.edu

V. Trouillet

Institute for Materials Research,

Karlsruhe Institute of Technology (KIT),

P.O. Box 3640, 76021 Karlsruhe, Germany

R. Truckenmüller

MIRA Institute for Biomedical Technology and Technical

Medicine, Dept. of Tissue Regeneration, University of Twente,

Drienerlolaan 5,

7522 NB Enschede, The Netherlands

\footnotetext{
A. Blau

Department of Neuroscience \& Brain Technologies,

The Italian Institute of Technology (IIT),

Via Morego, 30,

16163 Genoa, Italy

C. Ziegler

Department of Physics, University of Kaiserslautern,

Erwin-Schrödinger-Straße 56,

67663 Kaiserslautern, Germany
}

with anchored biomolecules micro structured scaffolds, e.g. curved and $\mu$-patterned substrates, can be fabricated. Here, we present a novel strategy for the fabrication of $\mu$-patterned scaffolds based on the "Substrate Modification and Replication by Thermoforming" (SMART) technology: The surface of a poly lactic acid membrane, having a low forming temperature of $60^{\circ} \mathrm{C}$ and being initially very cell attractive, was coated with a photopatterned layer of poly(L-lysine) (PLL) and hyaluronic acid (VAHyal) to gain spatial control over cell adhesion. Subsequently, this modified polymer membrane was thermoformed to create an array of spherical microcavities with diameters of $300 \mu \mathrm{m}$ for $3 \mathrm{D}$ cell culture. Human hepatoma cells (HepG2) and mouse fibroblasts (L929) were used to demonstrate guided cell adhesion. HepG2 cells adhered and aggregated exclusively within these cavities without attaching to the passivated surfaces between the cavities. Also L929 cells adhering very strongly on the pristine substrate polymer were effectively patterned by the cell repellent properties of the hyaluronic acid based hydrogel. This is the first time cell adhesion was controlled by patterned functionalization of a polymeric substrate with UV curable PLLVAHyal in thermoformed 3D microstructures.

Keywords Three-dimensional cell culture - Biopolymer . Patterning $\cdot$ Microthermoforming $\cdot$ Tissue engineering

\section{Introduction}

Two-dimensional (2D) cell cultures are routinely used as models to study the principles of cell biology. However, the commonly applied tissue culture plastic (TCP) substrates do rarely provide environments that resemble the in vivo 
conditions and thus are not accurate models of the natural situation (Prestwich 2007). Major drawbacks of these 2D cell culture systems are the lack of structural architecture, the limited material variety and no adequate control of many biochemical cues. Cells are forced to adapt to the flat, rigid substrate which may result in altered metabolism and reduced functionality (Beigel et al. 2008). Therefore, the simplified 2D technology does not allow for tissue engineering in which the maintenance of differentiation and cell type specific functions are playing a pivotal role (Cukierman et al. 2001).

In natural tissues, the extracellular matrix (ECM) surrounds nearly all cells by providing a complex threedimensional meshwork of fibers combined with many biochemical and physical cues. This microenvironment is specific for each cell type and controls cell viability, i.e. proliferation, differentiation and metabolism (Streuli 1999). The ECM is a highly hydrated, gel-like material composed of collagen-fibers, proteoglycans and glycoproteins (Lodish et al. 2000) with unique mechanical characteristics like stiffness, porosity and permeability.

It is well known that cells respond in vitro to chemically and topographically patterned surfaces, for a review see: (Lim and Donahue 2007). To mimic a natural threedimensional (3D) environment, advanced cell culture systems have been developed. These matrices or scaffolds are often porous substrates like sponges, fiber meshworks or microcapsules that can support cell growth, organization and differentiation on or within their structure (Barbucci et al. 2004; Ju et al. 2008; Lee et al. 2008). Another technique to culture cells three-dimensionally is the use of microwell arrays made of polymers (Bhatia and Chen 1999; Giselbrecht et al. 2006; Wu et al. 2006). In this context, microfabrication tools such as photolithography, plasma etching, soft lithography and microthermoforming are employed to produce microarrays and cell culture chips with characteristic and reproducible geometries to create organotypic structures (Borenstein et al. 2007). However, depending on the polymer material and its surface characteristics, cell adhesion inside of microcavities may only be controlled globally if no further cell confinement process is applied. As a consequence, cells statistically seeded from suspension onto a microwell array will usually also adhere to all exposed surfaces leading to a mixed population of a cell monolayer between the wells and a 3D cell culture situation inside the microcavities (Altmann 2008). This might lead to misinterpretations of some observations.

Several approaches to restrict cell adhesion to microcavities have been proposed. Mohr et al. coated a moulded polyurethane substrate with a protein resistant selfassembled monolayer of triethylene glycol-terminated alkanethiols between the wells and a Matrigel ${ }^{\mathrm{TM}}$ adsorbate inside the wells. This device was capable of maintaining undifferentiated human embryonic stem cells in culture for weeks without passaging (Mohr et al. 2006). Ochsner et al. passivated the plateau of a polydimethylsiloxane microstructure by inverted microcontact printing of poly $(\mathrm{L}$ lysine)-graft-poly(ethylene glycol). Subsequent incubation with a fibronectin solution selectively coated the wells with this cell-attractive protein to control the shape of single cells (Ochsner et al. 2007). A method called 'reactive microcontact printing' to control topography and localized presentation of extracellular matrix and transmembrane hematopoietic stem cell regulatory proteins was described by Lutolf (Lutolf et al. 2009). Our approach of fabricating microstructured cell culture substrates with a site-specific functionalization is based on the SMART-technology (Substrate Modification And Replication by Thermoforming) (Giselbrecht et al. 2006; Truckenmuller et al. 2008). SMART combines microtechnical thermoforming with a premodification of a planar polymer film with a high spatial resolution. Because the forming of the film occurs in its softened and not in its molten state pre-modifications are preserved. To guide cell adhesion locally we used a patterned hyaluronic acid (Hyal) layer as pre-modification. Hyaluronic acid, a major component of the natural ECM, is a water soluble polysaccharide. Hyal or its derivatives are usually deposited onto a surface by a sol-to-gel phase transformation. To obtain cell-inoculated scaffolds or drug-immobilized matrices, various chemical and physical cross linking and immobilization techniques of Hyal have been developed (Allison and Grande-Allen 2006; Ifkovits and Burdick 2007; Kogan et al. 2007). It was observed that most Hyal derivatives are cell and even protein repellent (Barbucci et al. 2003) and must therefore be modified to render them adhesive. A common approach to promote cell adhesion is to use artificial polymers like polylysine (Blau et al. 2001; Quirk et al. 2001). Picart et al. demonstrated that a polyelectrolyte layer made from polycationic poly(L-lysine) (PLL) and polyanionic Hyal acts as a ECM-like environment (Picart et al. 2001).

In this report, we modified this approach to generate thermomechanically processable films. The cell adhesion mediator, poly(L-lysine), was mixed with a photocurable Hyal derivative. This mixture was immobilized onto biocompatible PLA films (Desmet et al. 2009) by masked UV irradiation. The pre-patterned thin PLA film was then processed by microtechnical thermoforming to yield microwell arrays with an aligned pattern of cell repellent and attractive sites. The preservation of the cell adhesion pattern is possible due to the permanent material cohesion during the solid state forming process and, moreover, the surface patterns can be easily aligned to the obtained microwell topography of the thermoformed polymer membrane, to control cell adhesion with high precision even locally inside of each well. 


\section{Materials and methods}

\subsection{Synthesis of vinylated hyaluronic acid (VAHyal)}

The coupling of 4-vinyl aniline to sodium hyaluronate, was described by Matsuda et al. (Matsuda and Magoshi 2002). Hyaluronic acid (200 mg, MW $1.2-2.6 \times 10^{6} \mathrm{Da}$, Lifecore) was dissolved in $160 \mathrm{ml} \mathrm{Ca}{ }^{2+} / \mathrm{Mg}^{2+}$-free phosphate-buffered saline (PBS, Gibco). After the addition of 1-ethyl-3-[3-dimethylaminopropyl]carbodiimide hydrochloride (191 mg, $1 \mathrm{mmol}$, Sigma), and stirring for $15 \mathrm{~min}$, the solution was adjusted to $\mathrm{pH}=3$ with $1 \mathrm{~N} \mathrm{HCl}$ (Roth). 4-Vinylaniline (240 $\mu \mathrm{L}, 2 \mathrm{mmol}$, Aldrich) was added and the reaction mixture was stirred at $4{ }^{\circ} \mathrm{C}$ for $24 \mathrm{~h}$. Purification of the vinyl derivatized biomacromolecule (VAHyal) was carried out using a dialysis membrane (cut off MW: $12 \times 10^{3} \mathrm{Da}$, Sigma). Dialysis against distilled water for 3 days resulted in the complete removal of any non-transformed vinyl aniline and soluble side products from the solution. After freeze drying, the product was stored in a cool and dark place.

The identity and purity of VAHyal, a yellowish powder, was confirmed by ${ }^{1} \mathrm{H}-\mathrm{NMR}$ spectroscopy (Bruker, Avance, $250 \mathrm{MHz}$ ). The yield of vinylation, the number of styryl groups incorporated into hyaluronan, was calculated based on the UV absorbance of VA: $\varepsilon_{260 \mathrm{~nm}}=2.1 \times 10^{4} 1 \mathrm{~mol}^{-1} \mathrm{~cm}^{-1}$.

\subsection{Machinery and PLA-membrane processing}

The processing of the FDA compliant PLA membranes (thickness $25 \mu \mathrm{m}$, EarthFirst ${ }^{\circledR}$, Sidaplax) including surface treatments and microthermoforming is schematically shown in Fig. 1.

\subsubsection{Thermoforming mould insert}

Microstructured brass plates (RECORD Metall-Folien) of $300 \mu \mathrm{m}$ thickness with a mechanically milled array of $25 \times$ 25 circular through-holes of $350 \mu \mathrm{m}$ diameter were used as mould inserts. The thickness of these inserts corresponds to the maximum depth of the microcavities to be thermoformed. These thin mould inserts, shown in Fig. 1 (yellow), allowed the alignment of through-holes to the circle pattern of a corresponding photo mask, Fig. 1 (black/white), for a site-specific immobilization of VAHyal before thermoforming (see chapter 2.2.2).

\subsubsection{Preprocessing and immobilization of VAHyal on PLA membranes}

A PLA membrane, Fig. 1 (red), was fixed on the mould insert of the thermoforming machine, Fig. 1 (yellow). The fixed PLA film on the mould insert was plasma treated in a

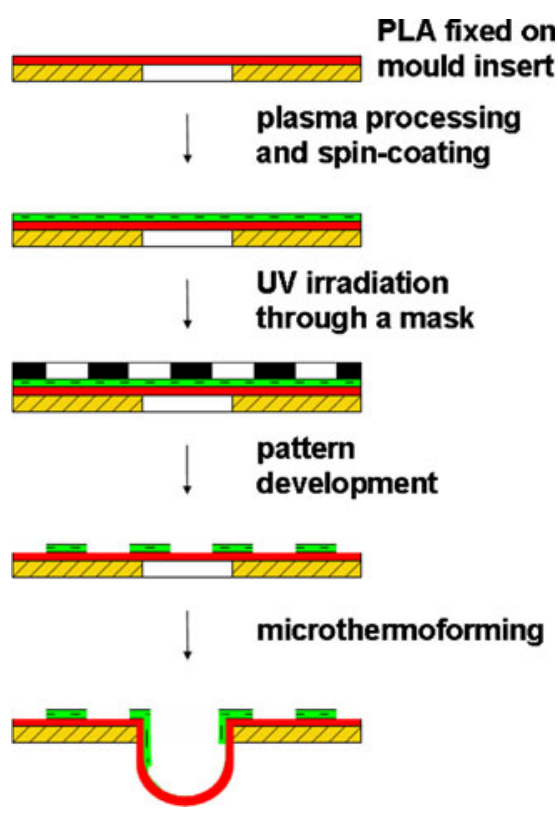

Fig. 1 Scheme of PLA film processing steps including $\mathrm{N}_{2}$-plasma treatment, spin-coating, masked UV irradiation, pattern development and microthermoforming. Red: PLA membrane, green: Hyaluronic acid based coating, yellow: brass mould insert, see also Fig. 2. The photo mask can be aligned with respect to the mould insert

radio frequency plasma generator (Oxford Plasma Technologies) with capacitive coupling (water cooled electrodes of $250 \mathrm{~mm}$ diameter and $35 \mathrm{~mm}$ distance) using the following parameters: $\mathrm{N}_{2}$ atmosphere, flow: 50 standard $\mathrm{cm}^{3} / \mathrm{min}$, pressure: $356 \mathrm{~Pa}$, radio frequency: $13.56 \mathrm{MHz}$, power: $150 \mathrm{~W}$, duration: $3 \mathrm{~min}$.

The photo polymerization process to graft either pure VAHyal or the mixture of VAHyal and $\varepsilon$-poly-L-lysine $(0.1 \% \mathrm{w} / \mathrm{v}$ solution in water, Sigma) on PLA films was initiated by Irgacure 2959 (Ic), (Ciba), and NVinylpyrrolidone (Vp), (Merck) as photoinitiators. The cytocompatibility of Irgacure 2929 was shown by Bryant et al. (Bryant et al. 2000). Leach et al. did show cross linking of a similar Hyal derivative (Leach et al. 2003).

Polymerization solutions:

(a) $15 \mathrm{mg} / \mathrm{mL}$ VAHyal, $1 \mathrm{mg} / \mathrm{mL} \mathrm{Vp}$, and $1 \mathrm{mg} / \mathrm{mL}$ Ic, in aqueous $\mathrm{EtOH}$;

(b) $0.1 \mathrm{mg} / \mathrm{mL}$ PLL, $1 \mathrm{mg} / \mathrm{mL} \mathrm{Vp}$, and $1 \mathrm{mg} / \mathrm{mL}$ Ic, in aqueous EtOH.

To produce mixed VAHyal/PLL coatings, a working solution (c) was mixed from the VAHyal stock solution, (a), and the PLL stock solution, (b), in a ratio of 2:1. Otherwise, pure (a) was used. (a) or (c) was spin-coated onto the plasma treated PLA membrane. The following spin-coating protocol was applied: $10 \mathrm{~s}$ at $200 \mathrm{rpm}$, followed by $60 \mathrm{~s}$ at $3000 \mathrm{rpm}$, followed by $5 \mathrm{~s}$ at 4,000 rpm. Subsequently, this layer, Fig. 1 (green), was irradiated by polychromatic UV 
light (HBO high pressure mercury lamp, Osram) to yield a water-insoluble photocrosslinked VAHyal, (pclVAHyal). Irradiation dose: $11 \mathrm{~J} \mathrm{~cm}^{-2}$ measured at $\lambda 365 \mathrm{~nm}$. In case of masked irradiations, the transparency of the modified PLA film allowed the alignment of irradiation masks with the through holes of the mould insert. Finally, the pattern was developed by washing the samples with demineralised $\mathrm{H}_{2} \mathrm{O}$. This process is schematically presented in Fig. 1 .

\subsubsection{Microthermoforming}

The microthermoforming process was carried out on an adapted hot embossing machine (WUM3, Jenoptik). As shown in Fig. 2, the mould insert holding the preprocessed polymer film with the photocrosslinked VAHyal structures was inserted between the upper plate and the lower counter plate of the thermoforming machine in such a way that the PLA film was facing the counter plate. Subsequently, the tool was closed and evacuated and the stack of polymer film and mould insert was pressed together and heated up to forming temperature $\left(60^{\circ} \mathrm{C}\right.$ for PLA). By applying pressurized nitrogen (2-3 MPa) via the counter plate, the softened PLA film was formed into the mould cavities composed of the through-holes of the mould insert and the upper brass plate. After cooling, the nitrogen pressure was released, the tool was opened, and the polymer film manually demoulded. In the presented experiments, the cavity depth of the thermoformed 3D polymer membranes was adjusted between 90-200 $\mu \mathrm{m}$ via the applied forming pressures.

\subsection{Surface analysis}

Contact angle measurements were performed on PLA samples with the sessile drop method using a goniometer (OCA10, dataphysics). To visualize the photocrosslinked VAHyal layers, staining with crystal violet $(0.5 \%$ in $20: 80$ $\mathrm{MeOH}: \mathrm{H}_{2} \mathrm{O}, 30 \mathrm{~min}$ ) was used. Thicker pclVAHyal layers stain violet, thin physisorbed layers can not be detected by this technique. In addition, X-ray photoelectron spectroscopy (XPS) was performed on a VG Scientific ESCALAB 5 with Alpha 110 analyser (Thermo Fisher Scientific),

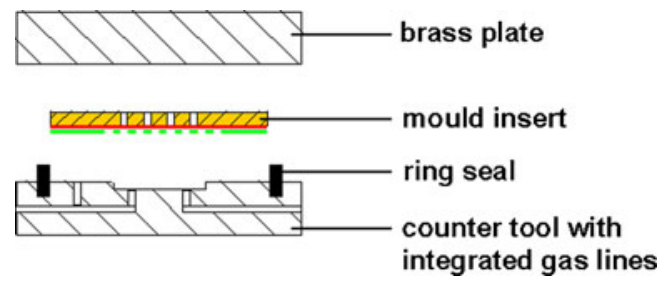

Fig. 2 Thermoforming process: brass mould insert (yellow) with fixed PLA film located between brass plate and counter tool. Red: PLA membrane, green: Hyaluronic acid based coating excitation by non-monochromatic $\mathrm{MgK}_{\alpha}$-radiation, power $200 \mathrm{~W}$, pass-energy $20 \mathrm{eV}$, electron emission angle $60^{\circ}$ to the surface normal. Data analysis was performed according to R. Hesse et al. (Hesse et al. 2007)

\subsection{Cell culture}

HepG2 cells (ATCC, strain: HB-8065) were cultured in Minimum Essential Medium, (MEM), (Gibco) supplemented with $10 \%$ foetal calf serum (PAA), $1 \%$ nonessential amino acids (PAA), $1 \%$ Na-pyruvate (PAA), $1 \%$ Glutamax (Gibco), 1\% penicillin/streptomycin (PAA) and $0.1 \%$ phenol red (Sigma). L929 cells (ATCC, strain: $\mathrm{C} 3 \mathrm{H} /$ an, designation: NCTC clone 929) were cultured in MEM supplemented with $10 \%$ foetal horse serum (ATCC) and $1 \%$ penicillin/streptomycin. Both cell lines were cultured in tissue culture flasks (BD Falcon) under culture conditions of $37^{\circ} \mathrm{C},>95 \%$ relative humidity, $5 \% \mathrm{CO}_{2}$.

The modified PLA-substrates were used in cell culture experiments after sterilization with $70 \%$ isopropanol and subsequent washing with PBS. The scaffolds were preincubated overnight with the correspondent cell culture medium. For cell seeding into the microstructured scaffolds, $300 \mu \mathrm{L}$ cell suspension with $5 \times 10^{5}$ cells were placed on the thermoformed area of the PLA film. Spreading of the suspension was avoided by a silicone ring placed on the PLA film. After three hours of pre-incubation with the cell suspension, cell culture medium was added to cover the PLA scaffold completely.

Cell adhesion and proliferation was monitored by staining with May-Grünwald's eosin methylene blue (Merck). Fluorescence micrographs were recorded on a confocal laser scanning microscope (Leica LSM TCS SP5) after rinsing the scaffold with PBS and cell staining with $0.5 \%$ Syto $^{\circledR}{ }^{\circledR}$ (Invitrogen) and $0.1 \%$ propidium iodide (Fluka) in MEM (30 min).

\section{Results and discussion}

\subsection{Chemical modifications}

The vinylated hyaluronic acid product was isolated as yellowish powder. The successful coupling of VA to Hyal was verified by NMR and UV/VIS spectroscopy. ${ }^{1} \mathrm{H}-\mathrm{NMR}$ (Bruker, $250 \mathrm{MHz}, \mathrm{D}_{2} \mathrm{O}, 25^{\circ} \mathrm{C}$ ) $\sigma=7.49$ (m, 4H, aromatic), $6.75(\mathrm{~m}, 1 \mathrm{H}$, vinyl-CH-), $5.22(\mathrm{~m}$, $1 \mathrm{H}$, vinyl- $\left.\mathrm{CH}_{2}-\right), 4.56\left(\mathrm{~m}, 2 \mathrm{H}, \mathrm{OH}-\mathrm{CH}_{2}-\right), 3.63-3.41$ (m, 10H, H-polysaccharide), $1.93\left(\mathrm{~s}, 3 \mathrm{H}, \mathrm{CH}_{3}-\right)$. The number of derivatized carboxylic groups was calculated from UV absorption data to be 2,5 per molecule. Successful UV initiated immobilization and cross linking of this derivative on PLA was observed. 


\subsection{Surface modifications}

As verified by contact angle measurement (Table 1), the hydrophilicity of the PLA film was increased by the $\mathrm{N}_{2}$-plasma treatments, thus improving the quality of the subsequently spin-coated films (Alves et al. 2008). Without the plasma treatment, inhomogeneous surface coatings were obtained on pristine PLA.

After spin-coating VAHyal or VAHyal/PLL onto the plasma treated PLA films, masked UV irradiation and subsequent washing was performed. VAHyal was immobilized on irradiated areas of the film as verified by crystal violet staining. Figure 3 shows a micrograph of the applied lithography mask overlaid with the obtained VAHyalpattern on a PLA membrane.

It was shown earlier that XP spectroscopy of hyaluronan coatings on polymers is a useful method to reveal successful immobilisation (Pasqui et al. 2007; Thierry et al. 2008; Mason et al. 2000; Suh et al. 2005). Herein XPSmeasurements of the PLA films with or without a VAHyal layer verified not only its binding to the PLA surface but also the influence of the photoinitiators $\mathrm{Vp}$ and Ic on the immobilization process. Table 2 shows the atomic concentrations calculated from XP spectra of differently treated PLA films.

In the case of immobilized VAHyal with Ic and Vp from solution (a) nitrogen was detected on PLA. Therewith, successful photocrosslinking of VAHyal was confirmed. Further, it was verified that the photoinitiators Irgacure and Vinylpyrrolidone did not modify the PLA surface, which otherwise may result in an altered cell adhesion: No indications were found in XP spectra (data not shown) and in the elemental ratios, see Table 2.

The spectra in Fig. 4 show the chemical shifts of the carbon $1 \mathrm{~s}$-core levels from the different atom species of pristine PLA, PLA after nitrogen plasma treatment, a reference sample of PLA after UV irradiation, plasma treated and UV irradiated PLA, and immobilized pclVAHyal on PLA.

We observed no nitrogen containing functionalities on $\mathrm{N}_{2}$-plasma treated PLA. It can be concluded, that the $\mathrm{N}_{2}$ plasma treatment did not insert any nitrogen into the PLA

Table 1 Contact angles of a 1:1 ethanol:water mixture on native and plasma treated PLA

\begin{tabular}{llll}
\hline PLA & PLA, $\mathrm{N}_{2}$-plasma treated & \\
\hline $\begin{array}{c}\text { Advancing } \\
\text { angle }\end{array}$ & $\begin{array}{c}\text { Receding } \\
\text { angle }\end{array}$ & $\begin{array}{c}\text { Advancing } \\
\text { angle }\end{array}$ & $\begin{array}{c}\text { Receding } \\
\text { angle }\end{array}$ \\
$50^{\circ} \pm 2^{\circ}$ & $26^{\circ} \pm 2^{\circ}$ & less than $10^{\circ}$, & \\
& & fully wettable & \\
& &
\end{tabular}

Reported data represent the average of five contact angle measurements with standard deviations

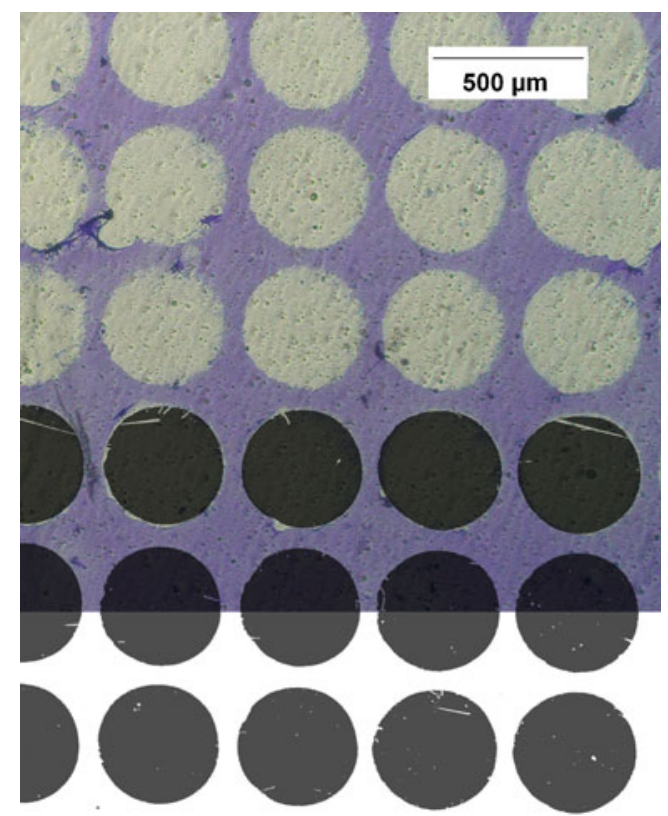

Fig. 3 Overlaid bright field micrographs: Bottom: Photolithography mask. Top: Resulting pclVAHyal pattern on PLA, stained with crystal violet

film, while it notably hydrophilized the surface, thereby facilitating the subsequent spin-coating process with the VAHyal-solution (Table 1).

\subsection{Thermoforming process}

During the thermoforming process the PLA film was heated up to $60^{\circ} \mathrm{C}$ and had to resist a pressure of 2 to $3 \mathrm{MPa}$. We investigated the behavior of a uniform and a patterned VAHyal layer on the PLA film after stretching in a thermoforming process at $60^{\circ} \mathrm{C}$ and $3 \mathrm{MPa}$ (according to Fig. 1).

As depicted in Fig. 5, showing a view into an array of cavities, a crystal violet staining of pclVAHyal on the ridges demonstrates that pclVAHyal withstood the heat of the

Table 2 Measured atomic concentrations from XP spectra for native PLA, nitrogen plasma treated PLA, UV irradiated PLA, plasma and UV treated PLA, photoinitiators Ic $+\mathrm{Vp}$ on plasma treated PLA with UV treatment and VAHyal/Ic/Vp on plasma treated PLA with UV treatment

\begin{tabular}{llll}
\hline Measured atomic concentrations [\%] for: & $\mathrm{C}$ & $\mathrm{O}$ & $\mathrm{N}$ \\
\hline PLA & 63.7 & 36.3 & 0.0 \\
PLA $+\mathrm{N}_{2}$ & 61.9 & 38.1 & 0.0 \\
PLA $+\mathrm{UV}$ & 63.2 & 36.8 & 0.0 \\
PLA $+\mathrm{N}_{2}+\mathrm{UV}$ & 62.7 & 37.3 & 0.0 \\
PLA $+\mathrm{N}_{2}+\mathrm{Ic}+\mathrm{Vp}+\mathrm{UV}$ & 61.1 & 38.9 & 0.0 \\
PLA $+\mathrm{N}_{2}+\mathrm{VAHyal} / \mathrm{Ic} / \mathrm{Vp}+\mathrm{UV}$ & 68.6 & 27.4 & 4.1 \\
\hline
\end{tabular}




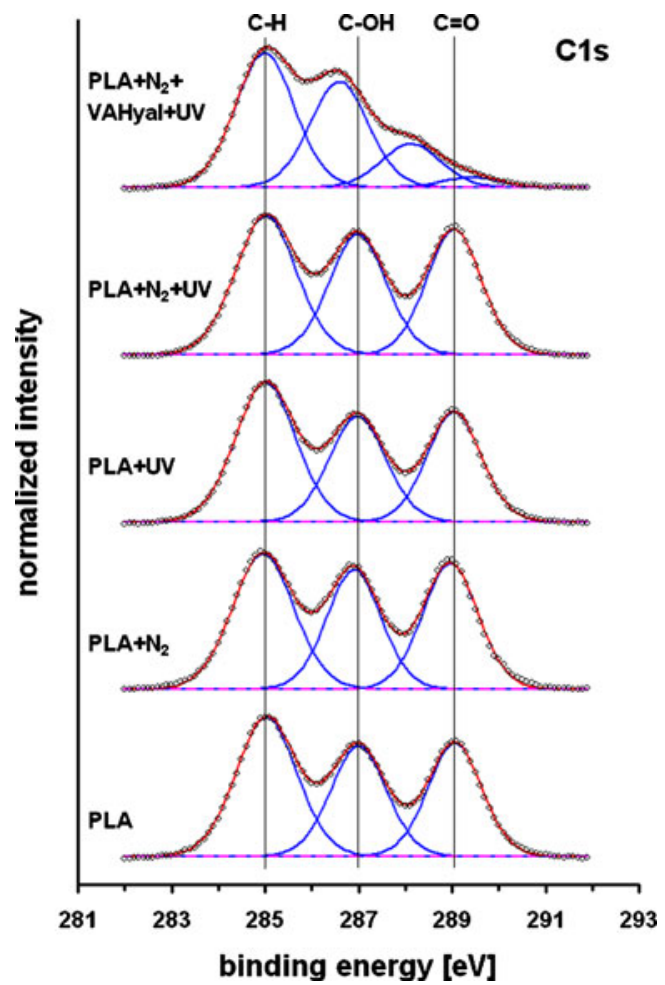

Fig. $4 \mathrm{C} 1 \mathrm{~s}$ XP spectra, normalized. Bottom to top: Pure PLA, PLA after nitrogen plasma treatment, PLA after UV exposure, PLA with plasma and UV treatment, PLA with plasma treatment and photoimmobilization of solution (a). Measured data: black dots, fit: blue and red lines

thermoforming process, while it was mechanically disrupted within the microcavities.

To rule out the possibility that pclVAHyal would decompose during the thermoforming process, the melting temperature of pclVAHyal was determined. At $180^{\circ} \mathrm{C}$ a slow decomposition of the polymer was observed; thus it can be assumed that thermoforming conditions for PLA membranes are compatible with pclVAHyal layers.

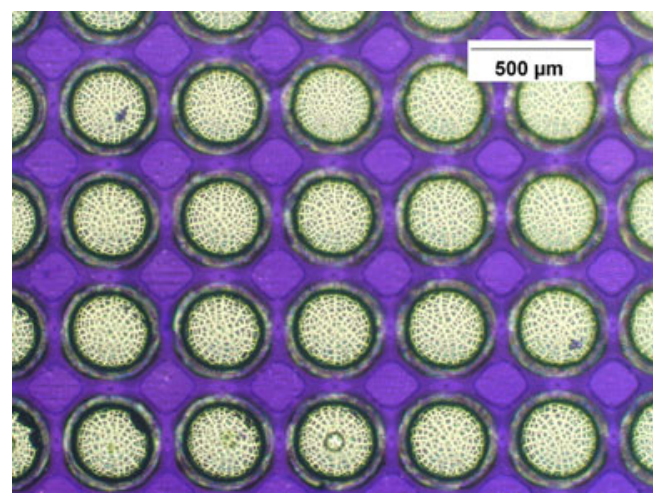

Fig. 5 PLA sample processed according to Fig. 1 (flood exposure) and stained with crystal violet, cavity depth: $170 \mu \mathrm{m}$

\subsection{Cell culture}

HepG2 hepatoma cells were cultured on VAHyal patterned PLA to validate it as a suitable cell culture substrate. L929 mouse fibroblasts, a cell line with high adhesiveness on many cell culture substrates like polystyrene, PLA, and even PDMS, were used to demonstrate the effectiveness of cell patterning. On PLA films that were uniformly covered with a pure pclVAHyal layer, neither HepG2 nor L929 cell adhesion was observed. Surprisingly, we found also no cell adhesion in any region of a patterned flat pclVAHyal film on PLA, comparable to the sample shown in Fig. 3, irrespective of local UV doses. In the non-irradiated areas no cross linking of the biopolymer should have occurred, leaving VAHyal fully water soluble and therefore those PLA regions should have remained cell-attractive. In these areas, an adsorbate of VAHyal on non-irradiated PLA surfaces could not be visualized by crystal violet staining, but the presence of a nitrogen peak in XP spectra (data not shown) clearly indicated the presence of a thin VAHyal layer.

To allow cell patterning via cell adhesion in nonirradiated areas of the substrate PLL was added to the VAHyal spin-coating solution (protocol based on working solution (c)) and a patterned surface of VAHyal mixed with PLL was prepared as described before. Again, the presence of a thin VAHyal/PLL coadsorbate on non irradiated areas was shown by XPS: Here, a nitrogen stoichiometric contribution of $2.3 \%$ was detected. However, in this case HepG2 cells did attach to the non-irradiated parts of the PLA film even with the thin chemisorbed VAHyal/PLL layer being present. Irradiated areas of the sample, covered with a cross linked layer of VAHyal/PLL remained free of cells, as shown in Fig. 6.

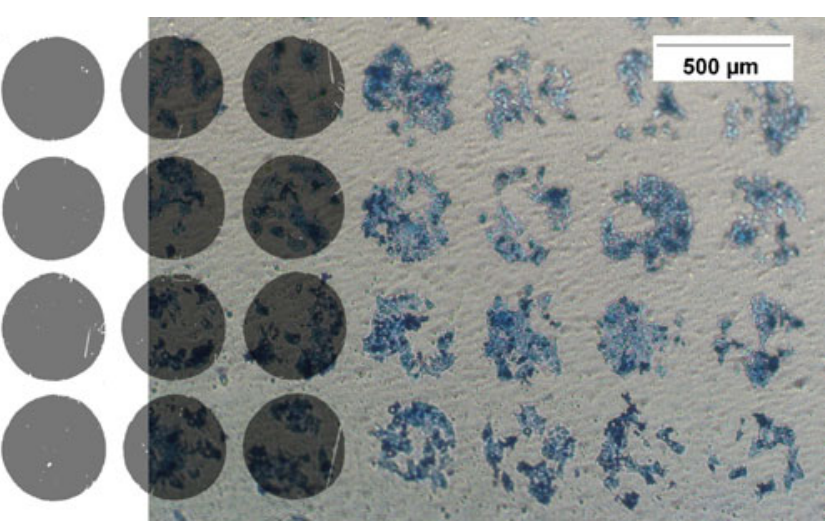

Fig. 6 Overlaid micrographs: Left: Circle mask. Right: PLA film after $\mathrm{N}_{2}$-plasma treatment and spin-coating with VAHyal/PLL, patterned UV irradiation (according to Fig. 1), and subsequent HepG2 cell culture, staining with May-Grünwald's eosin methylene blue after 2 days in vitro. PclVAHyal/PLL is not stained by this dye 

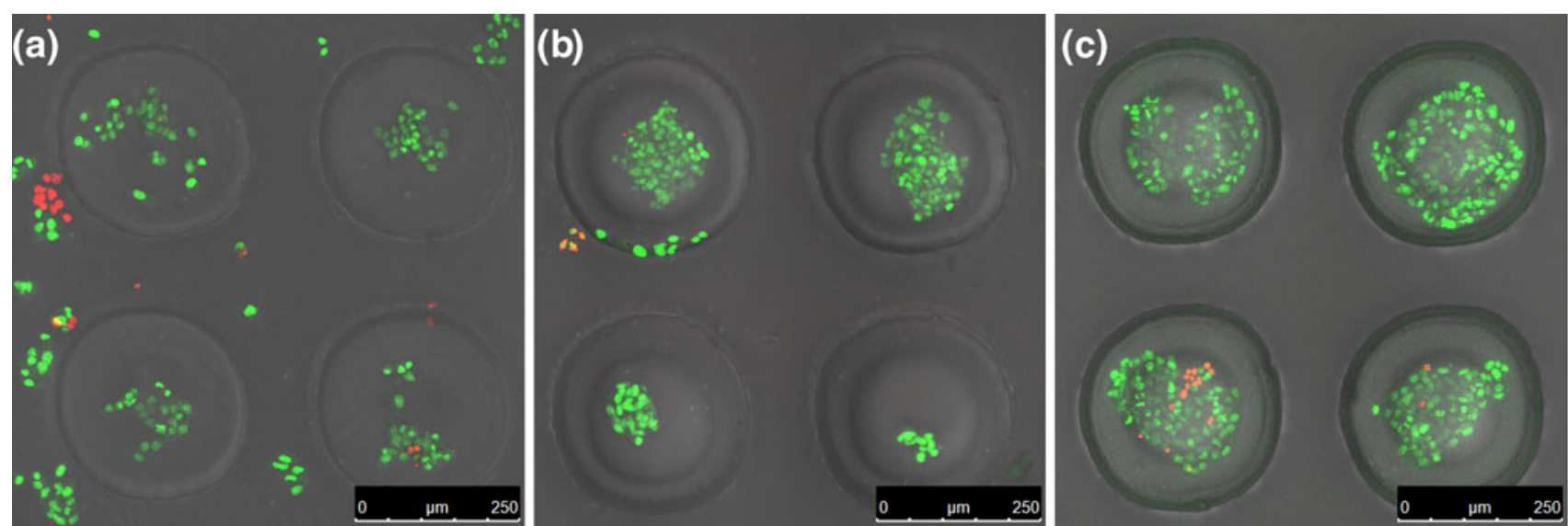

Fig. 7 HepG2 3 day in vitro culture on different scaffolds. Overlaid micrographs, (maximum projections): bright field, green fluorescence / Syto $16^{\circledR}$, red fluorescence / propidium iodide. (a) PLA, plasma treated, UV irradiated (aligned circle mask), and thermoformed substrate (cavity depth $130 \mu \mathrm{m}$ ) without coating. Note: Cells were located inside the

Having successfully patterned 2D PLA films, pclVAHyal/PLL pre-treated PLA films were subjected to the thermoforming process and tested with HepG2 and L929 cell cultures to demonstrate the more sophisticated manufacturing of patterned three-dimensional substrates.

Figure 7 shows the spreading of HepG2 cells on differently treated thermoformed PLA scaffolds in a combination of fluorescence and bright field images. Confocal microscopy in combination with live-dead staining (propidium iodide and Syto16) revealed that, independent of their distribution, the majority of the HepG2 cells was alive (green fluorescence) on all three substrate types, Fig. 7a-c, after 3 days in vitro.

Figure 7a shows a part of a three dimensional PLA scaffold which was plasma treated and exposed to UV

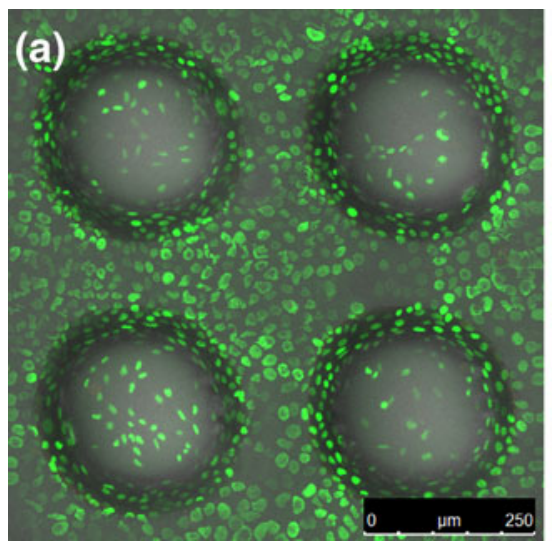

Fig. 8 L929 3 day in vitro culture on different scaffolds. Overlaid micrographs, (maximum projections): bright field, green fluorescence / Syto $16^{\circledR}$, red fluorescence / propidium iodide. (a) PLA, plasma treated, UV irradiated (flood exposure), and thermoformed substrate (cavity depth $150 \mu \mathrm{m}$ ) without coating. Note: Cells were located circular cavities and on the raised surfaces between the cavities. (b) PLA, plasma treated, VAHyal coated, UV irradiated (aligned circle mask), and thermoformed substrate (cavity depth $100 \mu \mathrm{m})$. (c) PLA, plasma treated, VAHyal/PLL coated, UV irradiated (aligned circle mask), and thermoformed substrate (cavity depth $150 \mu \mathrm{m}$ )

applying an aligned circle mask (UV light blocked for membrane areas which become reshaped to microcontainers). Irrespective of local UV exposure HepG2 cell adhesion and spreading was observed inside and between the thermoformed cavities.

To prepare the sample shown in Fig. 7b, VAHyal (solution (a)) was spin-coated onto plasma treated PLA, exposed to UV using the aligned circle mask and subsequently thermoformed (according to Fig. 1). In contrast to a flat PLA film where no cell adhesion was monitored at all for pclVAHyal patterns, the stretched areas of the PLA film inside the microcavities provided a cell attractive surface. As shown in Fig. 7b, cells were able to adhere to the PLA substrate within the ruptured pclVAHyal layer that had been generated by strong stress during the

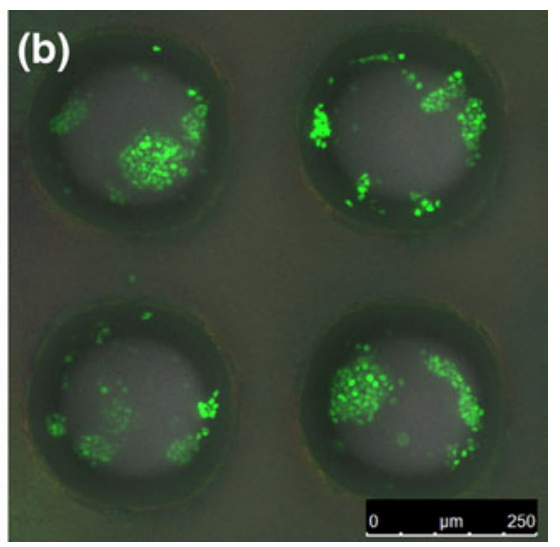

inside the circular cavities and on surfaces between the cavities. (b) PLA, plasma treated, VAHyal coated, UV irradiated (flood exposure), and thermoformed substrate (cavity depth $250 \mu \mathrm{m}$ ). Note cell adhesion is confined to the microwells 
Fig. 9 Thermoformed PLA samples with pclVAHyal/PLL pattern processed according to Fig. 1 (masked exposure, line mask). (a) cavity depth: $110 \mu \mathrm{m}$, cultured with HepG2 cells. (b) cavity depth: $100 \mu \mathrm{m}$, cultured with L929 cells. Staining with crystal violet after 3 days in vitro
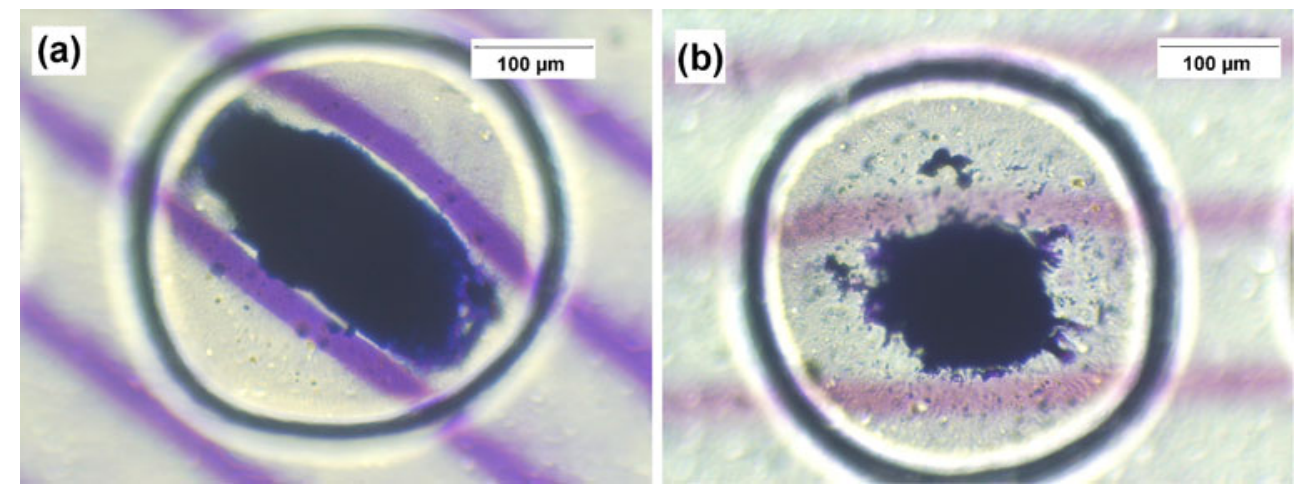

thermoforming process. The generated noncoherent VAHyal structures allowed for cell adhesion between the VAHyal fragments, (compare to Fig. 5). This side-effect of stretching, which was found for thermoformed patterned pclVAHyal substrates (Fig. 7b) and also for uniform, flood exposed, pclVAHyal layers (Fig. 5) opens an easy way to restrict cell adhesion to the microcavities.

If plasma treated PLA was spin-coated with VAHyal/ PLL, irradiated with UV through the aligned circle mask and then thermoformed, HepG2 cells exclusively adhered inside the cavities (see Fig. 7c). This agrees with the cell adhesion observed for HepG2 on flat PLA patterned with pclVAHyal/PLL (see Fig. 6). On elevated surfaces between cavities cells were completely absent (Fig. 7c).

As shown in Fig. 8, patterning of cell adhesion on curved PLA membranes was also obtained in case of L929 cells showing usually a strong adhesion on many polymer surfaces, even including PDMS. The reference sample shown in Fig. 8a exhibits a uniform cell attachment, whereas the basic patterning technique using integral UV exposure to immobilize a pclVAHyal layer which is locally disrupted inside the micro cavities during thermoforming allowed the confinement of cell adhesion in a straight forward approach (Fig. 8b).

Furthermore, we were able to define patterns with features sizes smaller than the dimensions of the microcavities. Thereby it was possible to control cell adhesion even locally within each cavity. Tests have shown the suitability of the applied method to create cell adhesion patterns on curved surfaces inside microcavities up to a cavity depth of about $150 \mu \mathrm{m}$ which corresponds to an average areal draw ratio of approx. 2. Figure 9 shows the results of the application of a mask with a line width of $20 \mu \mathrm{m}$, line spacing $100 \mu \mathrm{m}$, during UV irradiation process. VAHyal/PLL was immobilized on plasma treated PLA as described before, the sample was thermoformed and inoculated with HepG2 respectively L929 cells. After 3 days in vitro, staining with crystal violet revealed spatially controlled cell adhesion inside the microwells.

It was observed that cells initially spread between the pclVAHyal/PLL lines (Figs. 9a and b) and later grew across the pclVAHyal/PLL lines, until they finally filled the entire cavity as three dimensional aggregates. In contrast to other techniques (Lutolf et al. 2009; Mohr et al. 2006; Ochsner et al. 2007), the presented method based on the SMARTtechnology allows spatially controlled cell adhesion inside of microcavities.

\section{Conclusion}

It is generally accepted that three dimensional multicellular organoids represent a more realistic tissue model as compared to isolated single cells lacking cell/cell contacts or conventional cell monolayers in 2D configurations (Prestwich 2007, Beigel et al. 2008). Especially, in case of highly metabolizing primary liver cells, but even in case of conventionally hepatoma cells like HepG2, three dimensional cell culture configurations often outperform their classical 2D counterparts (Altmann 2008), e.g. we have

Table 3 Evaluation of substrate and coatings displayed by symbols with regard to cell adhesion (+) or no cell adhesion (-)

\begin{tabular}{lll}
\hline Substrate and coating: & Flat, non stretched areas & Curved thermoformed areas, areal draw ratio $<2^{\text {a }}$ \\
\hline PLA without coating & + & + \\
PLA + VAHyal (non irradiated) & - & - \\
PLA + pclVAHyal & - & - \\
PLA + VAHal/PLL (non irradiated) & + & + \\
PLA + pclVAHyal/PLL & - & + \\
\hline
\end{tabular}

${ }^{a}$ If areal draw ratios exceed 2, cell adhesion is possible in all cases. For details, see text 
shown recently that in HepG2 cytochrome oxidase II and III genes are upregulated more than fivefold in $3 \mathrm{D}$ vs. $2 \mathrm{D}$ culture (Gottwald et al. 2007). We presented an advancement of the SMART process by including a patterned biofunctionalization of the substrate preceding its forming. This allowed us to precisely define cell-adhesive and nonadhesive regions that can be independently controlled and partially separated from the mechanical alteration of surface topography. Thus, by combining the coating of a plasmaactivated PLA substrate with a mixture of VAHyal and PLL, its 2D UV patterning by photolithography followed by a final thermoforming process, a biochemically functionalized substrate for three-dimensional cell culture was obtained. The concept had been validated by a HepG2 cell culture model. HepG2 and L929 cells exclusively aggregated inside the non-irradiated yet VAHyal/PLL-coated, thermoformed microcavities, while unwanted adhesion and spreading between the cavities was prevented by photochemically crosslinked VAHyal/PLL coatings.

As summarized in Table 3, depending on the type of surface functionalization, cell adhesion could be controlled within and restricted to these microcavities. Compared to other microwell arrays (Lutolf et al. 2009; Ochsner et al. 2007) we were able to control adhesion of whole cell aggregates inside microcavities. Such strongly curved surfaces lay the foundation for more sophisticated cell culture experiments, such as the generation of spatially defined 3D co-cultures or the creation of patterns that induce cell polarity inside of an individual microwell.

Acknowledgement The authors would like to thank Michael Bruns for his help with XPS measurements, Alex Gerwald for contributing "SMART processed" membranes, and Sebastian Bartels for his assistance with cell culture and staining.

Open Access This article is distributed under the terms of the Creative Commons Attribution Noncommercial License which permits any noncommercial use, distribution, and reproduction in any medium, provided the original author(s) and source are credited.

\section{References}

D.D. Allison, K.J. Grande-Allen, Tissue Eng. 12, 2131 (2006)

B. Altmann, Entwicklung und Charakterisierung eines CellChipbasierten Bioreaktors zur dreidimensionalen Kultivierung von Zellen am Beispiel von humanen hepatozellulären Carcinomzelllinien und primären Hepatocyten aus der Ratte (Ruprecht-Karls Universität, Heidelberg, 2008). Thesis

C.M. Alves, Y. Yang, D. Marton, D.L. Carnes, J.L. Ong, V.L. Sylvia, D.D. Dean, R.L. Reis, C.M. Agrawal, J. Biomed. Mater. Res 87B, 59 (2008)
R. Barbucci, G. Leone, J. Biomed, Mater Res. B Appl. Biomater. 68, 117 (2004)

R. Barbucci, A. Magnani, S. Lamponi, D. Pasqui, S. Bryan, Biomaterials 24, 915 (2003)

J. Beigel, K. Fella, P.J. Kramer, M. Kroeger, P. Hewitt, Toxicol. In Vitro 22, 171 (2008)

S.N. Bhatia, C.S. Chen, Biomed. Microdevices 2, 131 (1999)

A. Blau, C. Weinl, J. Mack, S. Kienle, G. Jung, C. Ziegler, J. Neurosci. Meth. 112, 65 (2001)

J.T. Borenstein, E.J. Weinberg, B.K. Orrick, C. Sundback, M.R. Kaazempur-Mofrad, J.P. Vacanti, Tissue Eng. 13, 1837 (2007)

S.J. Bryant, C.R. Nuttelman, K.S. Anseth, J. Biomat. Sci. Polym. Edn 11, 439 (2000)

E. Cukierman, R. Pankov, D.R. Stevens, K.M. Yamada, Science 294, 1708 (2001)

T. Desmet, R. Morent, N. De Geyter, C. Leys, E. Schacht, P. Dubruel, Biomacromolecules 10, 2351 (2009)

S. Giselbrecht, T. Gietzelt, E. Gottwald, C. Trautmann, R. Truckenmuller, K.F. Weibezahn, A. Welle, Biomed. Microdevices 8, 191 (2006)

E. Gottwald, S. Giselbrecht, C. Augspurger, B. Lahni, N. Dambrowski, R. Truckenmüller, V. Piotter, T. Gietzelt, O. Wendt, W. Pfleging, A. Welle, A. Rolletschek, A. Wobus, K. F. Weibezahn, Lab Chip 7, 777 (2007)

R. Hesse, P. Streubel, R. Szargan, Surf. Interface Anal. 29, 381 (2007)

J.L. Ifkovits, J.A. Burdick, Tissue Eng. 13, 2369 (2007)

Y.M. Ju, K. Park, J.S. Son, J.J. Kim, J.W. Rhie, D.K. Han, J. Biomed. Mater. Res 85B, 252-2008 (2008)

G. Kogan, L. Soltes, R. Stern, P. Gemeiner, Biotechnol. Letters 29, 17 (2007)

J.B. Leach, K.A. Bivens, C.W. Patrick, C.E. Schmidt, Biotechnol. Bioeng. 82, 578 (2003)

J. Lee, M.J. Cuddihy, N.A. Kotov, Tissue Eng. Part B Rev 14, 61 (2008)

J.Y. Lim, H.J. Donahue, Tissue Eng. 13, 1879 (2007)

H. Lodish, A. Berk, L.S. Zipursky, P. Matsudaira, D. Baltimore, J.E. Darnell, Molecular cell biology, 4th edn. (Freeman, New York, 2000)

M.P. Lutolf, R. Doyonnas, K. Havenstrite, K. Koleckar, H.M. Blau, Integr. Biol. 1, 59 (2009)

M. Mason, K.P. Vercruysse, K.R. Kirker, R. Frisch, D.M. Marecak, G. D. Prestwich, W.G. Pitt, Biomaterials 21, 31 (2000)

T. Matsuda, T. Magoshi, Biomacromolecules 3, 942 (2002)

J.C. Mohr, J.J. de Pablo, S.P. Palecek, Biomaterials 27, 6032 (2006)

M. Ochsner, M.R. Dusseiller, H.M. Grandin, S. Luna-Morris, M. Textor, V. Vogel, M.L. Smith, Lab Chip 7, 1074 (2007)

D. Pasqui, A. Atrei, R. Barbucci, Biomacromolecules 8, 3531 (2007)

C. Picart, P. Lavalle, F.J.G. Cuisinier, P. Schaaf, J.C. Voegel, Langmuir 17, 7414 (2001)

G.D. Prestwich, J. Cell. Biochem 101, 1370 (2007)

R.A. Quirk, W.C. Chan, M.C. Davies, S.J. Tendler, K.M. Shakesheff, Biomaterials 22, 865 (2001)

C. Streuli, Curr. Opin. Cell. Biol 11, 634 (1999)

K.Y. Suh, J.M. Yang, A. Khademhosseini, D. Berry, T.-N.T. Tran, H. Park, R. Langer, J. Biomed. Mater Res. B 72, 292 (2005)

B. Thierry, F.M. Winnik, Y. Merhi, H.J. Griesser, M. Tabrizian, Langmuir 24, 11834 (2008)

R. Truckenmuller, S. Giselbrecht, C. van Blitterswijk, N. Dambrowsky, E. Gottwald, T. Mappes, A. Rolletschek, V. Saile, C. Trautmann, K.F. Weibezahn, A. Welle, Lab Chip 8, 1570 (2008)

Z.Z. Wu, Y. Zhao, W.S. Kisaalita, Colloids Surf. 52B, 14 (2006) 